\title{
molecules
}

ISSN 1420-3049

(C) 2007 by MDPI

Communication

www.mdpi.org/molecules

\section{How Many Drugs Are Catecholics}

\section{Da-Peng Yang, Hong-Fang Ji , Guang-Yan Tang, Wei Ren and Hong-Yu Zhang *}

Shandong Provincial Research Center for Bioinformatic Engineering and Technique, Center for Advanced Study, Shandong University of Technology, Zibo 255049, P. R. China

* Author to whom correspondence should be addressed; E-mail: zhanghy@sdut.edu.cn.

Received: 27 March 2007; in revised form: 23 April 2007 / Accepted: 25 April 2007 / Published: 30 April 2007

\begin{abstract}
By examination of the 8659 drugs recorded in the Comprehensive Medicinal Chemistry (CMC) database, 78 catecholics (including five pyrogallolics) were identified, of which 17 are currently prescribed by FDA. Through analyzing the substitutent patterns, $\mathrm{ClogPs}$ and $\mathrm{O}-\mathrm{H}$ bond dissociation enthalpies (BDEs) of the catecholic drugs, some molecular features that may benefit circumventing the toxicity of catecholics were revealed: i) strong electron-donating substituents are excluded; ii) $\operatorname{Clog} P<3$; iii) an energy penalty exists for quinone formation. Besides, the present analyses also suggest that the clinical usage and dosage of currently prescribed catecholic drugs are of importance in designing or screening catecholic antioxidants.
\end{abstract}

Keywords: Antioxidant, Catechol, Toxicity, Chemoinformatics, Density functional theory, Bond dissociation enthalpy

\section{Introduction}

Since reactive oxidative species (ROS) is implicated in the pathogenesis of many chronic diseases, such as cancer, cardiovascular and neurodegenerative diseases, finding novel antioxidants to combat ROS has attracted much attention [1,2]. To facilitate the discovery of antioxidants, some antioxidant pharmacophores have been identified, among which catechol has been given the most attention [3-9] The great antioxidant potential of catechol is attributed to the fact that the semiquinone radical derived 
from $\mathrm{H}$-atom donation of catechol can be stabilized by an intramolecular hydrogen bond and the electron-donating properties of the ortho-OH [3-5].

Although much effort has been devoted to designing novel antioxidants based on catechol, the potential toxicity of catecholics is a big concern, because the catechol-derived semiquinone radical can still donate a $\mathrm{H}$-atom to generate quinone, and during this process a superoxide anion radical may be produced [6-10]. In addition, quinones may act as Michael acceptors to react with various nucleophilic biomolecules producing cytotoxicity [6-10] Therefore, finding approaches to circumvent catecholics' potential toxicity is of great significance in antioxidant discovery. Considering the fact that catecholics (mainly in flavornoids)-rich vegetables, fruits and beverages are highly consumed in our daily life and some drugs also contain one or more catechol moieties, we speculate that catechol's toxicity might not be insurmountable. Thus, to get some insights into the structure-toxicity relationships of catechols, we attempted to explore the structural features of catecholic drugs, which may disclose some clues to surmounting the potential toxicity of catechols.

\section{Results and Discussion}

Thanks to the continuing efforts of medicinal chemists, most drugs have been documented in a database named Comprehensive Medicinal Chemistry (CMC), in which 8,659 entities are recorded [11]. The screening in CMC identified 78 drugs containing one or more catechol moiety, of which five contain one or more pyrogallol groups (Supplementary Material - Table S1) [12]. 45 pharmacological effects, including antioxidant activity (shared by three drugs), were found for the 78 drugs. The most common pharmacological effects are bronchodilator (shared by 12 drugs), adrenergic (shared by nine drugs), antiparkinsonian (shared by seven drugs) and antihypertensive (shared by seven drugs). The fact that nearly $1 \%$ of drugs possess one or more catechol (or pyrogallol) moiety strongly suggests that the toxicity of catechol group is controllable. More importantly, through searching U.S. Food and Drug Administration (FDA) database (http://www.accessdata.fda.gov/scripts/cder/drugsatfda/ index.cfm), 19 agents approved by the FDA were found (Supplementary Material - Table S2), of which 17 are still prescriptible and 13 are injectable (Figure 1, Supplementary Material - Table S2).

Considering the rigorous examination of FDA, the 17 FDA-approved agents are of special interest in the present study. Although their structures are diverse, they can be classified into five types according to the substitutent patterns (I-V, labeled in different colors in Figure 1). Type I consists of a catechol moiety and a carbon chain at the para-position of hydroxyl group. Types II and III have a seven- and a six-member ring attached to the catecholic ring, respectively. As these side chains and rings are weak electron-donating groups, they have slight influence on the electronic properties of the catechol moieties of types I-III. In contrast, types IV and $\mathbf{V}$ have a strong electron-withdrawing substitutent, $\mathrm{NO}_{2}$ [13], at the ortho-position of hydroxyl and a side chain at the para-position of hydroxyl group. It can be inferred that $\mathrm{NO}_{2}$ will greatly influence the electronic behaviors of the catechols. It is interesting to note that strong electron-donating substituents are excluded in these drugs, which agrees well with the previously summarized structure-toxicity relationships for phenols that generally electron-releasing groups tend to enhance the phenols’ cytotoxicity [14]. 
Figure 1. Structures, pharmacological effects and ClogPs of currently FDA-prescribed catecholic drugs. According to the substitutent patterns, these molecules are classified into 5 types (type I, in green; type II, in cyan; type III, in orange; type IV, in blue; type $\mathbf{V}$, in red).<smiles>NCCc1ccc(O)c(O)c1</smiles>

dopamine (adrenergic) Clog $P: 0.17$<smiles>CC(N)C(O)c1ccc(O)c(O)c1</smiles>

levonordefrin (vasoconstrictor, adrenergic) $\mathrm{C} \log P$ : -0.68<smiles>NCC(O)c1ccc(O)c(O)c1</smiles>

norepinephrine (adrenergic) Clog $P:-0.99$<smiles>CC(N)(C(=O)CO)c1ccc(O)c(O)c1</smiles>

methyldopa (antihypertensive) ClogP: -2.26<smiles>CC(N)C(O)c1ccc(O)c(O)c1</smiles>

nordefrin (vasoconstrictor) Clog $P$ : -0.68<smiles>CCC(NC(C)C)C(O)c1ccc(O)c(O)c1</smiles>

isoetharine (bronchodilator) ClogP: 0.99<smiles>NC(Cc1ccc(O)c(O)c1)C(=O)O</smiles>

levodopa (antiparkinsonian) ClogP: -2.82<smiles>CC(C)NCC(O)c1ccc(O)c(O)c1</smiles>

isoproterenol (adrenergic) $\mathrm{C} \log P: 0.53$

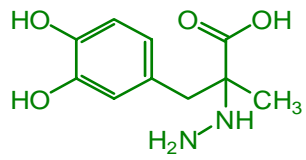

carbidopa (decarboxylase inhibitor) Clog $P$ : -1.13

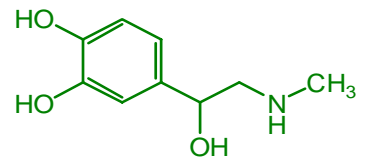

epinephrine

(bronchodilator, adrenergic) Clog $P$ : -1.37<smiles>CCOC(=O)C(C)(N)Cc1ccc(O)c(O)c1</smiles>

methyldopate (antihypertensive) ClogP: 0.55<smiles>CC(CCc1ccc(O)cc1)NCCc1ccc(O)c(O)c1</smiles>

dobutamine (cardiotonic) ClogP: 1.75

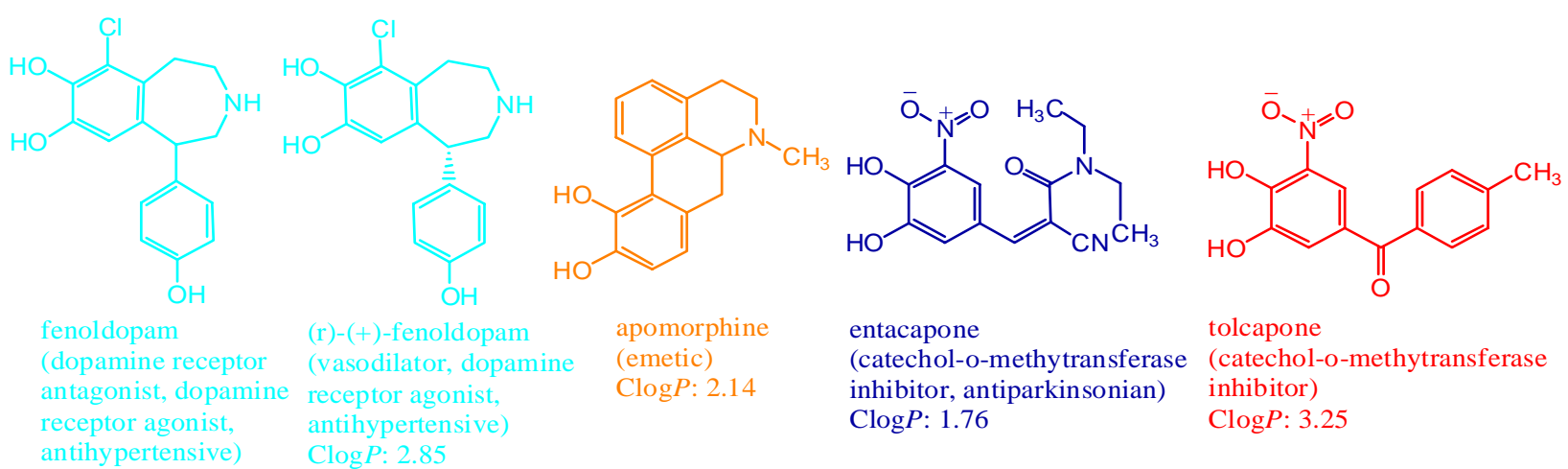

The hydrophilicity of the 17 FDA-prescribed catecholic drugs was also estimated by calculating the logarithm of their $n$-octanol-water partition coefficients $(\log P$ ) with the fragmental methodology proposed by Hansch and Leo [15]. The parameter is termed ClogP and was calculated using the CS ChemOffice software (Ultra ver. 10.0) [16]. From Figure 1, it can be seen that the ClogPs of all catecholics (except tolcapone) are $<3$, consistent with the current notion that hydrophilicity is beneficial to improving the safety of phenols [17].

Furthermore, to gain deeper insight into the structure-toxicity relationships of catecholics, we resorted to quantum chemical calculations. Recently, Wright and co-workers indicated that since the toxicity of catecholics is related to their quinone formation potential, there should exist some correlation between the second $\mathrm{O}-\mathrm{H}$ bond dissociation enthalpy (BDE) of catechols and their toxicity, 
namely, the higher the second O-H BDE is, the less toxic the catechols should be [6-10]. For instance, owing to the energy penalty in abstracting the second H-atom in 2,3-naphthalenediol, it is safer than 1,2- and 1,4-naphthalenediol (Figure 2) [8]. These findings stimulated our interest in calculating the $\mathrm{O}-\mathrm{H}$ BDEs of the catecholic drugs.

Figure 2. O-H BDEs (in kcal $/ \mathrm{mol}$ ) of catechol and five types (I-V) of catecholic drugs, corresponding to donate first (labeled as 1) and second (labeled as 2) H-atoms.

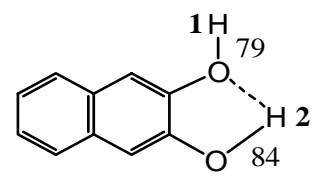

2,3-naphthalenediol<smiles>[R]Oc1ccccc1O[TlH]</smiles>

catechol

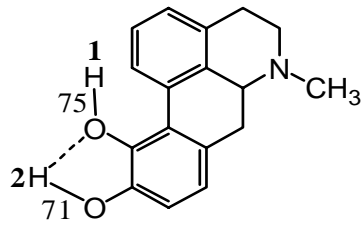

III<smiles></smiles>

1,2-naphthalenediol
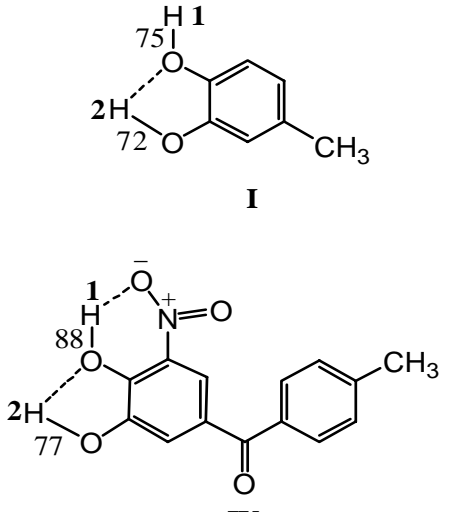

IV

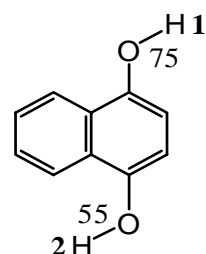

1,4-naphthalenediol

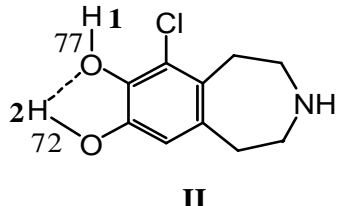

II

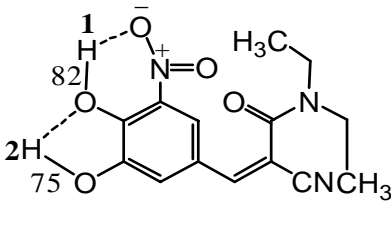

To facilitate the calculation of O-H BDEs, the side chains of type I catecholics were replaced by a methyl group and the phenolic moiety of type II catecholics was deleted, as they have little influence on the BDE values. To compare with the results of Wright et al. [8], the same method, namely (RO)B3LYP/6-311+G(2d,2p)//AM1/AM1, was employed to do the calculations [18]. The detailed procedures are as follows. First, semiempirical method AM1 [19] was used to optimize the molecular geometries and determine the vibrational frequencies. Then, single-point electronic energies (SPEs) were calculated by (RO)B3LYP functional [20,21] at 6-311+G(2d,2p) level. According to the definition of BDE, O-H BDE $=H_{\mathrm{r}}+H_{\mathrm{h}}-H_{\mathrm{p}}$, in which, $H_{\mathrm{r}}$ is the enthalpy of radical generated through $\mathrm{H}$-abstraction reaction, $H_{\mathrm{h}}$ is the enthalpy of $\mathrm{H}$-atom, -0.50000 hartree, and $H_{\mathrm{p}}$ is the enthalpy of parent molecule. Molecular enthalpy $(H)$ consists of (RO)B3LYP/6-311+G(2d,2p)-calculated SPE, AM1derived thermal contributions to enthalpy (TCE, in which the vibrational contributions including zero point vibrational energy were scaled by a factor of 0.973) [8]. All of the quantum chemical calculations were accomplished by the Gaussian 98 program [22].

From Figure 2, it can be seen that the O-H BDEs of types I-III catecholics are very similar to those of catechol, suggesting that both $\mathrm{H}$-atoms are ready to donate, which is in accordance with the above inference that the weak electron-donating groups have slight influence on the electronic properties of catechol moieties. However, the first O-H BDEs of types IV and V catecholics are much higher than that of catechol, although the second BDEs are still comparable to that of catechol, which reflects the strong electron-withdrawing property of $\mathrm{NO}_{2}$. Hence, the low toxicity of types $\mathbf{I V}$ and $\mathbf{V}$ catecholics is 
very likely to be associated with the energy penalty in the formation of quinones. Interestingly, this differs slightly from the tactic of Wright et al., which depended on the increment of the second BDE $[8,9]$. As the presently revealed methodology comes at the cost of losing the radical-scavenging ability of catecholics, to design or screen catecholic antioxidants, the strategy of Wright et al. is preferred. However, it remains elusive why types I-III catecholics also display low toxicity. The reason may lie in the dosage of these catecholic drugs. Thus, we suggest that the clinical usage and dosage of the currently prescribed catecholic drugs may be considered in designing catecholic antioxidants.

\section{Conclusions}

In summary, the present analyses identified 78 catecholic drugs in the CMC and 17 catecholics as currently prescribed FDA drugs, which strongly suggests that the potential toxicity of catechol is not insurmountable. Through examining the substituent patterns, ClogPs and O-H BDEs of these molecules, some molecular features that may benefit circumventing the toxicity of catecholics were identified: i) strong electron-donating substituents are excluded; ii) $\operatorname{Clog} P<3$; iii) an energy penalty exists for quinone formation. Besides, the present analyses also suggest that the clinical usage and dosage of currently prescribed catecholic drugs are of importance in designing or screening catecholic antioxidants.

Last but not least, the present findings also have important implications for designing multipotent antioxidants. Following the paradigm shift in drug design, i.e., from "one-drug, one-target" to "onedrug, multiple-targets" [23-27], finding multifunctional antioxidants represents a new trend in antioxidant discovery [28]. The multipotent antioxidants are expected to hit other targets than ROS implicated in various chronic diseases, such as cancer, cardiovascular and neurodegenerative diseases [28-31]. The diverse structures and pharmacological effects of 78 catecholic drugs implicate that catechol can be well merged with other pharmacophores to bring multiple pharmacological effects. Therefore, catechol is a promising starting point for designing or screening multipotent agents with antioxidant effect and beyond [32].

\section{Acknowledgements}

This study was supported by National Basic Research Program of China (2003CB114400) and National Natural Science Foundation of China (30100035 and 30570383).

\section{Supplementary Material}

The Supplementary Material for this paper, including structures, pharmacological effects, usage, strength and marketing status of catecholic drugs is available via the Internet at http://www.mdpi.org/molecules/papers/12040878sm.pdf.

\section{References and Notes}

1. Shahidi, F., Ed.; Natural Antioxidants: Chemistry, Health Effects, and Applications; The American Oil Chemists' Society: Champaign, IL, 1997. 
2. Thomas, C. E. In Handbook of Synthetic Antioxidants; Packer, L.; Cadenas, E., Eds.; Marcel Dekker, Inc.: New York, 1997; pp. 1-52.

3. Zhang, H.-Y. Structure-activity relationships and rational design strategies for radical- scavenging antioxidants. Curr. Comput.-Aided Drug Des. 2005, 1, 257-273.

4. Zhang, H.-Y. Theoretical investigation on free radical scavenging activity of 6,7dihydroxyflavone. Quant. Struct.-Act. Relat. 2000, 19, 50-53.

5. Zhang, H.-Y.; Sun, Y.-M.; Wang, X.-L. Substituent effects on O-H bond dissociation enthalpies and ionization potentials of catechols: a DFT study and its implications in rational design of phenolic antioxidants and elucidation of structure-activity relationships for flavonoid antioxidants. Chem. Eur. J. 2003, 9, 502-508.

6. Foti, M. C.; Johnson, E. R.; Vinqvist, M. R.; Wright, J. S.; Barclay, L. R. C.; Ingold, K. U. Naphthalene Diols: A new class of antioxidants intramolecular hydrogen bonding in catechols, naphthalene diols, and their aryloxyl radicals. J. Org. Chem. 2002, 67, 5190-5196.

7. Hussain, H. H.; Babic, G..; Durst, T.; Wright, J. S.; Flueraru, M.; Chichirau, A.; Chepelev, L. L. Development of novel antioxidants: design, synthesis, and reactivity. J. Org. Chem. 2003, 68, 7023-7032.

8. Chichirau, A.; Flueraru, M.; Chepelev, L. L.; Wright, J. S.; Willmore, W. G.; Durst, T.; Hussain, H. H.; Charron, M. Mechanism of cytotoxicity of catechols and a naphthalenediol in PC12-AC cells: the connection between extracellular autoxidation and molecular electronic structure. Free Radic. Biol. Med. 2005, 38, 344-355.

9. Flueraru, M.; Chichirau, A.; Chepelev, L. L.; Willmore, W. G.; Durst, T.; Charron, M.; Barclay, L. R. C.; Wright, J. S. Cytotoxicity and cytoprotective activity in naphthalenediols depends on their tendency to form naphthoquinones. Free Radic. Biol. Med. 2005, 39, 1368-1377.

10. Bolton, J. L.; Trush, M. A.; Penning, T. M.; Dryhurst, G.; Monks, T. J. Role of quinones in toxicology. Chem. Res. Toxicol. 2000, 13, 135-160.

11. Comprehensive Medicinal Chemistry, Release 2004.1; MDL Information Systems Inc.: San Leandro, CA, 2004.

12. Thanks to the additional hydroxyl group, pyrogallol is less toxic than catechol, which has been well addressed by Wright and co-workers: Flueraru, M.; So, R; Willmore, W. G.; Poulter, M. O.; Durst, T.; Charron, M.; Wright, J. S. Cytotoxicity and cytoprotective activity of naphthalenediols in rat cortical neurons. Chem. Res. Toxicol. 2006, 19, 1221-1227.

13. The Hammett constants $\sigma_{\mathrm{m}}$ and $\sigma_{\mathrm{p}}$ of $\mathrm{NO}_{2}$ are 0.71 and 0.78 , respectively: Hantsch, C.; Leo, A.; Taft, R. W. A survey of Hammett substituent constants and resonance and field parameters. Chem. Rev. 1991, 91, 165-195.

14. Verma, R. P.; Kapur, S.; Barberena, O.; Shusterman, A.; Hansch, C. H.; Selassie, C. D. Synthesis, cytotoxicity, and QSAR analysis of X-thiophenols in rapidly dividing cells. Chem. Res. Toxicol. 2003, 16, 276-284.

15. Hansch, C.; Leo, A. J. Substituent Constants for Correlation Analysis in Chemistry and Biology; Wiley: New York, NY, 1979.

16. CambridgeSoft, Cambridge, MA, USA, 2006.

17. Moridani, M. Y.; Siraki, A.; O’Brien, P. J. Quantitative structure toxicity relationships for phenols in isolated rat hepatocytes. Chem.-Biol. Interact. 2003, 145, 213-223. 
18. Although this method is not very accurate for calculating catecholic O-H BDEs [3], it is suitable to help draw qualitative conclusions.

19. Dewar, M. J. S.; Zoebisch, E. G.; Healy, E. F.; Stewart, J. J. P. Development and use of quantum mechanical molecular models. 76. AM1: a new general purpose quantum mechanical molecular model. J. Am. Chem. Soc. 1985, 107, 3902-3909.

20. Lee, C.; Yang, W.; Parr, R. G. Development of the Colle-Salvetti correlation-energy formula into a functional of the electron density. Phys. Rev. B. 1988, 37, 785-789.

21. Becke, A. D. A new mixing of Hartree-Fock and local density-functional theories. J. Chem. Phys. 1993, 98, 1372-1377.

22. Frisch, M. J.; Trucks, G. W.; Schlegel, H. B.; Scuseria, G. E.; Robb, M. A.; Cheeseman, J. R.; Zakrzewski, V. G.; Montgomery, J. A.; Stratmann, R. E.; Burant, J. C.; Dapprich, S.; Millam, J. M.; Daniels, A D.; Kudin, K. N.; Strain, M. C.; Farkas, O.; Tomasi, J.; Barone, V.; Cossi, M.; Cammi, R.; Mennucci, B.; Pomelli, C.; Adamo, C.; Clifford, S.; Ochterski, J.; Petersson, G. A.; Ayala, P. Y.; Cui, Q.; Morokuma, K.; Salvador, P.; Dannenberg, J. J.; Malick, D. K.; Rabuck, A. D.; Raghavachari, K.; Foresman, J. B.; Cioslowski, J.; Ortiz, J. V.; Baboul, A. G.; Stefanov, B. B.; Liu, G.; Liashenko, A.; Piskorz, P.; Komaroni, I.; Gomperts, R.; Martin, R. L.; Fox, D. J.; Keith, T.; Al-Laham, M. A.; Peng, C. Y.; Nanayakkara, A.; Challacombe, M.; Gill, P. M. W.; Johnson, B.; Chen, W.; Wong, M. W.; Andres, J. L.; Gonzalez, C.; Head-Gordon, M.; Replogle, E. S.; Pople, J. A. Gaussian 98, Revision A.11; Gaussian, Inc.: Pittsburgh, PA, 2001.

23. Morphy, R.; Kay, C.; Rankovic, Z. From magic bullets to designed multiple ligands. Drug Discov. Today. 2004, 9, 641-651.

24. Mencher, S. K.; Wang, L. G. Promiscuous drugs compared to selective drugs (promiscuity can be a virtue). BMC Clin. Pharmacol. 2005, 5, 3.

25. Morphy, R.; Rankovic, Z. Designed multiple ligands. An emerging drug discovery paradigm. $J$. Med. Chem. 2005, 48, 6523-6543.

26. Keith, C. T.; Borisy A. A.; Stockwell, B. R. Multicomponent therapeutics for networked systems. Nat. Rev. Drug Discov. 2005, 4, 71-78.

27. Hopkins, A. L.; Mason, J. S.; Overington, J. P. Can we rationally design promiscuous drugs? Curr. Opin. Struct. Biol. 2006, 16, 127-136.

28. Zhang, H.-Y.; Yang, D.-P.; Tang, G.-Y. Multifunctional antioxidants: from screening to design. Drug Discov. Today 2006, 11, 749-754.

29. Zhang, H.-Y. One-compound-multiple-targets strategy to combat Alzheimer's disease. FEBS Lett. 2005, 579, 5260-5264.

30. Zhang, H.-Y.; Yang, D.-P.; Ji, H.-F. Naturally occurring multipotent anti-Alzheimer agents. Expert Opin. Drug Discov. 2006, 1, 269-277.

31. Zhang, H.-Y. Same causes, same cures. Biochem. Biophys. Res. Commun. 2006, 351, 578-581.

32. It is noticeable that five of the 78 catecholic drugs, i.e., baicalein, fenoldopam, gossypol, oleuropein, (r)-(+)-fenoldopam, possess three or more pharmacological effects (Supplementary Information - Table S1).

(C) 2007 by MDPI (http://www.mdpi.org). Reproduction is permitted for noncommercial purposes. 